\title{
Mycolipenates and Mycolipanolates of Trehalose from Mycobacterium tuberculosis
}

\author{
By D. E. MINNIKIN, ${ }^{*}$ G. DOBSON ${ }^{1}$ D. SESARDIC ${ }^{2} \dagger$ AND \\ M. RIDELL ${ }^{3}$ \\ ${ }^{1}$ Department of Organic Chemistry, The University, Newcastle upon Tyne NE1 7RU, UK \\ ${ }^{2}$ MRC Unit for Laboratory Studies of Tuberculosis, Royal Postgraduate Medical School, \\ Hammersmith Hospital, Ducane Road, London W12 OHS, UK \\ ${ }^{3}$ Department of Medical Microbiology, University of Göteborg, Guldhedsgatan 10, \\ $S-41346$ Göteborg, Sweden
}

(Received 2 November 1984; revised 4 February 1985)

\begin{abstract}
Analysis of the lipids of Mycobacterium tuberculosis, by thin-layer chromatography, revealed the presence of two families of novel glycolipids each having two closely-related members but differing widely in polarity. The least and most polar families of lipids were characterized from $M$. tuberculosis strains $\mathrm{C}$ and $\mathrm{H} 37 \mathrm{Rv}$, respectively; all were based on trehalose, the least polar pair of glycolipids having more long-chain substituents than the more polar pair. The acyl substituents of the least polar of the four glycolipids were mainly straight-chain $C_{16}$ and $C_{18}$ acids and 2,4,6-trimethyltetracos-2-enoic $\left(\mathrm{C}_{27}\right.$-mycolipenic) acid, and the second least polar glycolipid contained major amounts of 3-hydroxy-2,4,6-trimethyltetracosanoic $\left(\mathrm{C}_{27}\right.$-mycolipanolic) acid in addition to these non-hydroxylated acids. The relatively polar pair of glycolipids were analysed together and released mainly straight-chain $\mathrm{C}_{16}$ and $\mathrm{C}_{18}$ acids, $\mathrm{C}_{27^{-}}$ mycolipanolic acid, minor amounts of $\mathrm{C}_{25}$ - and $\mathrm{C}_{27}$-mycolipenic acids and major proportions of an acid having the chromatographic properties of 2,4-dimethyldocosanoic acid. The most polar pair of glycolipids co-chromatographed with glycolipid antigens previously detected in Mycobacterium bovis BCG.
\end{abstract}

\section{INTRODUCTION}

Mycobacteria synthesize a wide range of unusual lipid molecules which are associated with the outer regions of the cell envelope (reviewed by Minnikin, 1982). Mycolipenic and mycolipanolic acids (Fig. 1), isolated from Mycobacterium tuberculosis (Coles \& Polgar, 1968), are examples of unusual mycobacterial fatty acids. The parent complex lipids based on these fatty acids have not, however, been identified. In this communication it is shown that mycolipenates and mycolipanolates (Fig. 1) occur naturally in two distinct families of glycolipids based on trehalose and that one family of these glycoplipids also contains major amounts of an acyl substituent with the properties of 2,4-dimethyldocosanoic acid (Fig. 1).

\section{METHODS}

Strains. Mycohacterium tuberculosis strain C, grown on glycerol-based Sauton's medium, was obtained as freezedried heat-killed cells from the Central Veterinary Laboratory, Weybridge, UK. M. tuberculosis H37Rv was cultivated as surface cultures at $37^{\circ} \mathrm{C}$ on Sauton's medium with $2 \%$ glycerol for 6 weeks in $200 \mathrm{ml}$ conical flasks, killed by autoclaving, washed and freeze-dried, yielding about $0.3 \mathrm{~g}$ dry weight from each flask.

$\dagger$ Present address: Department of Clinical Pharmacology, Royal Postgraduate Medical School, Hammersmith Hospital, Ducane Road, London W12 0HS, UK.

Abbretiation: TMS, trimethylsilyl. 


\author{
Mycolipenic acid $\mathrm{CH}_{3} \cdot\left(\mathrm{CH}_{2}\right)_{m} \cdot \mathrm{CH}_{\mathrm{C}}^{\mathrm{CH}_{3}} \mathrm{CH}_{2} \cdot \mathrm{CH} \cdot \mathrm{CH}=\mathrm{C} \cdot \mathrm{COOH}$ \\ $\mathrm{L} \quad \mathrm{L}$ \\ Mycolipanolic acid $\mathrm{CH}_{3} \cdot\left(\mathrm{CH}_{2}\right)_{n} \cdot \stackrel{\mathrm{CH}_{3}}{\mathrm{C}} \cdot \mathrm{CH}_{2} \cdot \stackrel{\mathrm{C}}{\mathrm{CH}} \cdot \stackrel{\mathrm{C}}{\mathrm{C}} \cdot \stackrel{\mathrm{OH}}{\mathrm{C}} \mathrm{H} . \mathrm{COOH}$ \\ $\mathrm{L} \quad \mathrm{L}$ erythro \\ 2,4-Dimethyldocosanoic acid $\mathrm{CH}_{3} \cdot\left(\mathrm{CH}_{2}\right), \stackrel{\mathrm{CH}_{3}}{\mathrm{C}_{\mathrm{C}}} \cdot \mathrm{CH}_{2} \stackrel{\mathrm{CH}_{\mathrm{C}}}{\mathrm{H}_{3}} \mathrm{COOH}$
}

Fig. 1. Formulae of multimethyl-branched long-chain acids from M. tuberculosis.

\begin{abstract}
Lipid extraction. Dry biomass $(50 \mathrm{mg})$ was extracted according to a recently developed procedure which produces distinct non-polar and polar fractions (Minnikin et al., 1984; Dobson et al., 1985). The method involved extraction with a biphasic mixture of aqueous methanol and petroleum ether (b.p. $60-80^{\circ} \mathrm{C}$ ) to give non-polar lipids in the upper organic layer. The remaining cells and aqueous methanol were then treated essentially according to the established lipid extraction procedure of Bligh \& Dyer (1959) using monophasic chloroform/methanol/water, the extracts being diluted with additional chloroform and water to give a biphasic mixture with polar lipids in the lower organic layer.
\end{abstract}

Lipid chromatography. Thin-layer chromatography (TLC) was carried out on $6.6 \times 6.6 \mathrm{~cm}$ pieces of Merck 5554 silica gel 60 TLC aluminium sheets. All lipids were detected by spraying with $5 \%$ ethanolic molybdophosphoric acid with heating at $180^{\circ} \mathrm{C}$ for $15 \mathrm{~min}$ and glycolipids were identified with $\alpha$-naphthol/sulphuric acid followed by heating for $15 \mathrm{~min}$ at $100^{\circ} \mathrm{C}$ (Dobson et al., 1985). Short-wave UV light (254 nm) was used to detect UV-absorbing lipids. The non-polar lipid extracts were examined by two dimensional (2D) TLC, developing three times with petroleum ether (b.p. $\left.60-80^{\circ} \mathrm{C}\right) /$ acetone $(92: 8, v / v)$ in the first direction followed by toluene/acetone $(95: 5, v / v)$ once in the second direction (Dobson et al., 1985). Polar and non-polar extracts were analysed by 2D TLC with chloroform/methanol/water $(100: 14: 0 \cdot 8$, by vol.) followed by chloroform/acetone/methanol/water $(50: 60: 2 \cdot 5: 3$, by vol.) (Dobson et al., 1985). Glycolipids were isolated by preparative TLC on $1 \mathrm{~mm}$ layers of Merck 7748 silica gel $60 \mathrm{PF}_{25++366}$ with suitable combinations of the above solvent systems.

Glycolipid analysis. Glycolipids (1-5 mg) were deacylated according to the procedure of Kates (1972) to produce fatty acid methyl esters and water-soluble glycosides. Fatty acid esters were examined by TLC using toluene/acetone $(99: 1, \mathrm{v} / \mathrm{v})$ and compared with straight-chain methyl esters and mycolipenic and mycolipanolic methyl ester standards (Coles \& Polgar, 1968). Components isolated by preparative TLC were examined by gas chromatography (GC) using a Perkin-Elmer F11 flame ionization gas chromatograph fitted with a $3 \cdot 2 \mathrm{~mm}$ o.d. stainless steel column $(1 \mathrm{~m})$ packed with $2.5 \%$ OV-1 silicone on $80-100$ mesh Chromosorb G AW-DMCS. Nitrogen was used as carrier gas with isothermal operating temperatures of $220^{\circ} \mathrm{C}$ and $235^{\circ} \mathrm{C}$ for nonhydroxylated esters having $<24$ or $>24$ carbons, respectively. Hydroxy acid methyl esters were converted to trimethylsilyl (TMS) ethers (Kates, 1972) and examined by GC at $235^{\circ} \mathrm{C}$. Mass spectrometry with an AEI MS 9 instrument was used to identify the fatty acid esters of higher molecular weight.

Water-soluble glycosides and mono- and disaccharide standards were examined by TLC using acetonitrile/water $(90: 10, \mathrm{v} / \mathrm{v})$ and detection with $\alpha$-naphthol/sulphuric acid (Jacin \& Mishkin, 1965) and alkaline silver nitrate (Bate-Smith \& Westall, 1950) sprays for all sugars and reducing sugars, respectively. Glycosides were analysed as TMS ethers by GC at $270^{\circ} \mathrm{C}$ with a $6 \mathrm{~m}$ column packed with the $\mathrm{OV}-1$ phase described above, and at $240{ }^{\circ} \mathrm{C}$ with a $3 \mathrm{~m}$ column packed with $3 \%$ OV-17 on 80-100 mesh Chromosorb WHP. Component sugars of glycosides were identified by conversion to alditol acetates, using the procedure of Albersheim et al. (1967). GC of alditol acetates was carried out at $270{ }^{\circ} \mathrm{C}$ using a $6 \mathrm{~m}$ column packed with $10^{\circ}$ Silar $10 \mathrm{C}$ on $100-120$ mesh Gas Chrom Q.

Infra-red spectra were recorded for $2-5 \%$ solutions in cyclohexane or carbon tetrachloride with a Perkin-Elmer 257 instrument.

\title{
RESULTS
}

Examination by TLC of non-polar lipid extracts of $M$. tuberculosis $\mathrm{C}$ and $\mathrm{H} 37 \mathrm{Rv}$ revealed the presence of glycolipids which absorbed UV light, suggesting the possible presence of long-chain acyl components such as the mycolipenic acids (Fig. 1). The 2D TLC system used for analysis of the non-polar lipids showed the presence of two UV absorbing glycolipids (A and $\mathrm{B}$ ) having $R_{F}$ 
values of 0.19 and 0.10 in the first direction and 0.44 and 0.28 for the second solvent system. Use of the alternative polar 2D TLC system detected two closely-overlapping glycolipids (C and D) in both non-polar and polar lipid extracts, the $R_{F}$ values being 0.20 and 0.17 in the first solvent and 0.21 and 0.17 for the second direction. The relatively non-polar glycolipids were particularly abundant in $M$. tuberculosis $\mathrm{C}$ and the more polar glycolipids were prominent in the H37Rv strain; typical chromatograms are available elsewhere (Dobson et al., 1985). The components of the non-polar glycolipid fraction from $\boldsymbol{M}$. tuberculosis $\mathrm{C}$ were readily separated by preparative TLC but the polar glycolipids from $M$. tuberculosis $\mathrm{H} 37 \mathrm{Rv}$ were isolated together, the presence of two components being best demonstrated by the absorption of UV light by the upper spot.

The least polar (A) and most polar (B) components of the relatively non-polar glycolipid from $M$. tuberculosis $\mathrm{C}$ were deacylated and the long-chain methyl esters produced were examined by TLC. Both glycolipids released long-chain components co-chromatographing with straightchain fatty acid methyl esters $\left(R_{F} 0.65\right)$ and authentic mycolipenate $\left(R_{F} 0.76\right)$ but an additional component chromatographing with mycolipanolate $\left(R_{F} 0 \cdot 16\right)$ was obtained from glycolipid $\mathrm{B}$. Long-chain esters were isolated by preparative TLC and examined by GC, using a TMS derivative of the suspected mycolipanolate. The GC results for non-hydroxylated esters, summarized in Table 1, show that the long-chain substituents of glycolipids $\mathrm{A}$ and $\mathrm{B}$ are principally straight-chain $\mathrm{C}_{16}$ and $\mathrm{C}_{18}$ acids and $\mathrm{C}_{25^{-}}$and $\mathrm{C}_{27}$-mycolipenates. GC analysis of the TMS derivatives of the hydroxy esters from glycolipid $B$ showed proportions $(12 \cdot 2,3.5$ and $84.3 \%$ ) of components (retention times $10.5,14.7$ and $19.4 \mathrm{~min}$ ) corresponding to $\mathrm{C}_{25^{-}}, \mathrm{C}_{26}$ - and $\mathrm{C}_{27}$-mycolipanolates, respectively. The assignments were supported by mass spectrometry of the methyl esters; the structures corresponded to $\mathrm{C}_{25^{-}}$and $\mathrm{C}_{27}$-mycolipenates (Fig. 1, $m=15$ and 17) and $\mathrm{C}_{27}$-mycolipanolate (Fig. 1, $n=17$ ).

Deacylation of the two closely related polar glycolipids (C and D) from M. tuberculosis H37Rv gave a TLC pattern of long-chain fatty acid methyl esters similar to that from glycolipid B. GC analyses of the non-hydroxylated esters, however, showed that, in addition to straight-chain, mycolipenic and mycolipanolic esters, major proportions of another high molecular weight acid derivative were recorded (Table 1). Comparison of the chromatographic behaviour of this latter acid with those of multimethyl-branched mycocerosic acids from $M$. tuberculosis (Minnikin et al., 1983) indicated that its structure was 2,4-dimethyltetracosanoate (Fig. 1); mass spectrometry supported this assignment. The suspected mycolipanolates from glycolipids $C$ and D were analysed by mass spectrometry of TMS ethers; the principal component corresponded to a $\mathrm{C}_{27}$-mycolipanolate (Fig. $1, n=17$ ) with a minor mass spectral peak corresponding to a $\mathrm{C}_{25^{-}}$ mycolipanolate being present.

The water-soluble glycosides resulting from alkaline deacylation of all the glycolipids under study were analysed by TLC and all co-chromatographed $\left(R_{F} 0 \cdot 10\right)$ with a standard of trehalose and gave no reaction with the alkaline silver nitrate reagent for reducing sugars. The TMS ethers of all the glycosides and the trehalose standard had the same retention times ( $36 \cdot 5$ and $25 \cdot 2 \mathrm{~min}$ ) on $6 \mathrm{~m} \mathrm{OV}-1$ and $3 \mathrm{~m} \mathrm{OV}-17$ columns; TMS ether derivatives of cellobiose, gentiobiose, lactose and maltose had different retention times. Acid hydrolysis of the glycosides and conversion to alditol acetates gave a derivative which had the same retention time $(80.3 \mathrm{~min})$ as glucitol hexaacetate; derivatives of galactitol and mannitol had retention times of 73.6 and $65.5 \mathrm{~min}$, respectively.

The ratios of the various long-chain components in glycolipids A and B were estimated as follows. The total long-chain non-hydroxylated fatty acid methyl esters for each glycolipid were examined by GC on the $1 \mathrm{~m} \mathrm{OV}-1$ column using an initial period of $15 \mathrm{~min}$ at $170^{\circ} \mathrm{C}$ followed by programming at $2{ }^{\circ} \mathrm{C} \mathrm{min}-1$ to $250{ }^{\circ} \mathrm{C}$. The ratio of mycolipanolates to mycolipenates, for glycolipid $\mathrm{B}$, was determined by treating the total long-chain extract with TMS reagent and GC, isothermally, at $235^{\circ} \mathrm{C}$. These analyses indicated that the molar ratio of high molecular weight branched acids (mycolipenic and 2,4-dimethyl) to $<\mathrm{C}_{24}$ straight-chain acids was approximately 6:1 for glycolipid $A$, suggesting the presence of six substituents with $>C_{24}$ acids and single substituents having $<\mathrm{C}_{24}$ acids. For glycolipid $\mathrm{B}$ the ratios of $>\mathrm{C}_{24},<\mathrm{C}_{24}$ and mycolipanolic acids was approximately $5: 1: 1$ indicating the presence of five $>\mathrm{C}_{24}$ non-hydroxylated substituents and single $<\mathrm{C}_{24}$ and mycolipanolate substituents. 


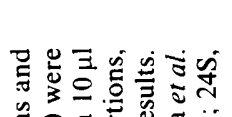

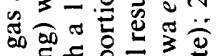

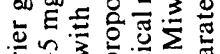

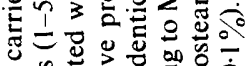

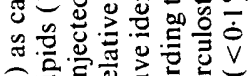

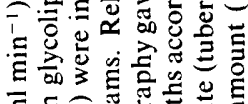

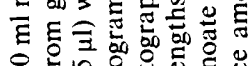

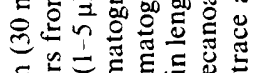

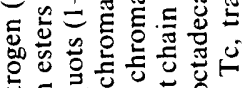

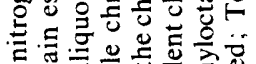

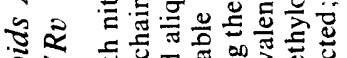

灾全

के जे ज्ञ

¿

ปั

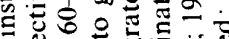

은

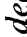

ป象

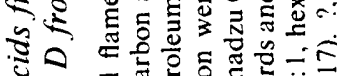

ช人 0

₹ป

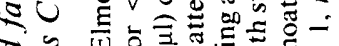

过

¿

ڤे

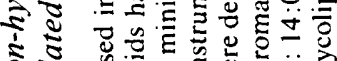

ఏ 仓

จั

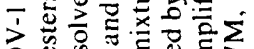

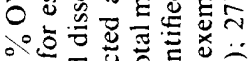

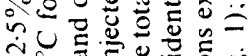

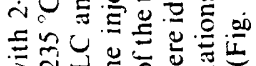

उति

离导

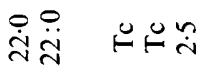

ํํㅇ 불

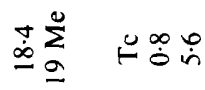

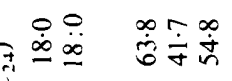

$u^{\prime \prime}$

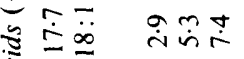

竎

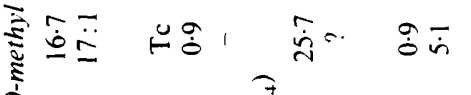

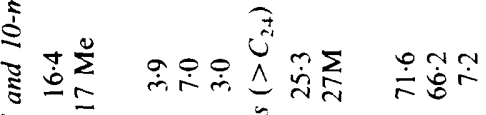

离

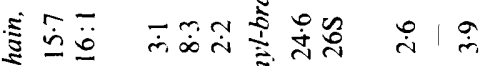

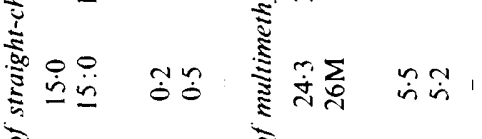

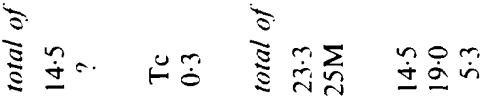

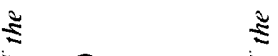

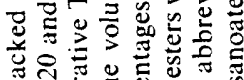

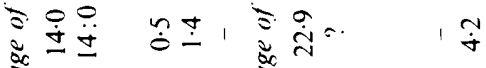

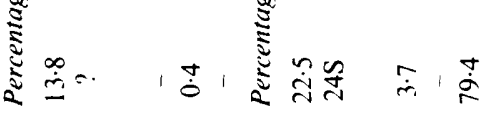

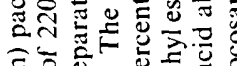

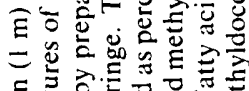

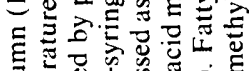

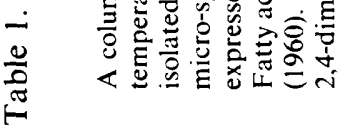

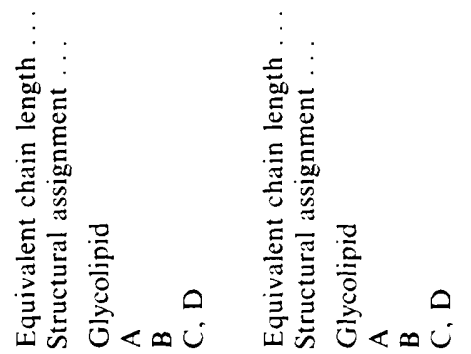


Similar experiments were not done for the polar glycolipids C and D since they were not separated efficiently by TLC. The polarity of lipids C and D, and the enhanced hydroxyl absorptions ( 3610 and $3480 \mathrm{~cm}^{-1}$ ) in their infra-red spectra, suggested that fewer acyl substituents were present than in glycolipids A and B. Both these latter lipids did show sharp, but weak, infra-red absorptions, indicating the presence of at least one hydroxyl group in each compound.

\section{DISCUSSION}

The mycolipenic acids (Fig. 1), also termed phthienoic acids, have been known as characteristic components of the tubercle bacillus for many years (see reviews by Goren \& Brennan, 1979; Minnikin, 1982). Related mycolipanolic acids (Fig. 1) were also recognized some years ago by Coles \& Polgar (1968). The present paper shows, for the first time, that these very unusual fatty acids occur as components of glycolipids isolated from the free lipids of $M$. tuberculosis. The two strains were chosen for study since the non-polar (A and B) and polar (C and D) pairs of glycolipids were particularly abundant in strains $C$ and $H 37 R v$, respectively. Unpublished studies indicate, however, that all four glycolipids are detectable in many representatives of $M$. tuberculosis and possibly in certain strains of $M$. bovis (see Minnikin, 1982). Indeed the polar glycolipids $C$ and $D$ correspond to an antigenic phosphorus-free glycolipid fraction studied by Reggiardo et al. (1981) in extracts of $M$. bovis BCG, but further studies are needed to confirm that these are the same lipids. It should be noted that the infra-red spectrum of an uncharacterized glycolipid described by Noll (1957) was closely similar to that recorded for glycolipid $\mathrm{A}$.

A number of glycolipids based on trehalose have been previously characterized from mycobacteria (for a review see Minnikin, 1982). The glycolipids under study are also derivatives of trehalose, acylated mainly with combinations of conventional straight-chain, mycolipenic, mycolipanolic and 2,4-dimethyl saturated acids. Further studies are required to locate the positions of the acyl groups in the present glycolipids. The detection in glycolipids $\mathrm{C}$ and $\mathrm{D}$ of high proportions of one of these latter acids having the chromatographic properties of 2,4dimethyldocosanoate (Fig. 1; Table 1) requires comment. Such an acid, termed $\mathrm{C}_{24^{-}}$ mycosanoate, has been previously isolated from M. tuberculosis (Cason et al., 1964) and its positive (dextro-) optical rotation suggested a 2-L, 4-L configuration; the same absolute configuration as that present in mycolipenates and mycolipanolates (Fig. 1). The phthioceranates are another class of dextrorotatory methyl-branched acids from the sulpholipid fraction of M. tuberculosis (Goren \& Brennan, 1979; Minnikin, 1982); but they have over 30 carbons and 5 to 10 methyl branches.

The mycocerosic acids from waxes of $M$. tuberculosis are mainly $\mathrm{C}_{27}-\mathrm{C}_{32}$ acids with 2 and 4 methyl branches but they are levorotatory with opposite absolute configurations to those of the mycolipenates (see Minnkin, 1982). A dextrorotatory $\mathrm{C}_{22}$-mycosanoic (2-L,4-L-dimethyleicosanoic) acid has been characterized from $M$. aurum (Rafidinarivo et al., 1982) but it was associated with an oligosaccharide distinct from trehalose.

It appears, therefore, that the saturated acid from glycolipids $\mathrm{C}$ and $\mathrm{D}$ is possibly a dextrorotatory $\mathrm{C}_{24}$-mycosanoate (Cason et al., 1964) since it is found in the same lipids as $\mathrm{C}_{25^{-}}$ and $\mathrm{C}_{27}$-mycolipenates. Such an acid would be on the biosynthetic pathways that are considered to operate for mycolipanolates and mycolipenates (Fig. 1) as reviewed by Minnikin (1982). Condensation of $\mathrm{C}_{24}$-mycosanoate (2,4-dimethyldocosanoate; Fig. 1) with a propionate derivative would give a keto acid derivative which on reduction would produce $\mathrm{C}_{27^{-}}$ mycolipanolate (Fig. 1, $n=17$ ); dehydration of the latter would lead to $\mathrm{C}_{27}$-mycolipenate (Fig. $1, m=17$ ). Acids related to the mycolipenic acids (Fig. 1), but having an additional cis-double bond in position 15, were characterized from $M$. tuberculosis and termed mycolipodienic acids by Coles \& Polgar (1969). These latter acids were not identified in the present study, possibly because they were originally isolated as relatively minor components from much larger lipid extracts (Coles \& Polgar, 1969). 
Minnikin (1982) suggested that complex lipids having multimethyl-branched acyl components may be located on the outside of mycobacterial outer membrane systems based on a mycolic acid matrix covalently linked to an arabinogalactan. The more polar glycolipids $\mathrm{C}$ and $\mathrm{D}$ may possibly be lipid antigens since they co-chromatograph with such lipids isolated by Reggiardo et al. (1981) from $M$. bovis BCG. The more heavily acylated pair of glycolipids A and B may then have a role, in conjunction with waxes such as the dimycocerosates of the phthiocerol family, in providing an inert lipid base among which the more active lipids are distributed on the surface of the mycobacterial cell.

G. D. was supported by a studentship from the British Leprosy Relief Association (LEPRA) and the work was aided by a grant from the IMMLEP Steering Committee of the UNDP/World Bank/WHO Special Programme for Research and Training in Tropical Diseases (T/16/181/L4/29). Mass spectra were recorded by S. H. Addison and P. Kelly. A grant from the University of Newcastle upon Tyne Research Fund to D. E. M. is acknowledged.

\section{REFERENCES}

Albersheim, P.. Neirns, D., ENGlish, P. D. \& Karr, A. (1967). A method for the analysis of sugars in plant cell wall polysaccharides by gas liquid chromatography. Carbohydrate Research 5, 340-345.

Bate-Smith, E. C. \& Westall, R. G. (1950). Chromatographic behaviour and chemical structure. I. Some naturally occurring phenolic substances. Biochimica et hiophysica acta 4, 427--440.

Bligh, F. G. \& Dyer, W. J. (1959). A rapid method of total lipid extraction and purification. Canadian Journal of Biochemistry and Physiology 37, 911-917.

Cason, J., Lange, G. L. \& URSCheler, H. R. (1964). Isolation of 2,4-dimethyldocosanoic acid from the lipids of tubercle bacillus. Tetrahedron 20, 1955. 1961.

Coles, L. \& Polgar, N. (1968). The mycolipanolic acids. Journal of the Chemical Societr (C), 1541-1544.

Coles, L. \& Polgar, N. (1969). The mycolipodienic acids. Journal of the Chemical Society (C), 2327.

Dobson, G., Minnikin, D. E., Parlett, J. H., GoOdfellow, M., Ridell, M. \& MaGnusson, M. (1985). Systematic analysis of complex mycobacterial lipids. In Chemical Methods in Bacterial Sistematics, pp. 237 265. Fdited by M. Goodfellow \& D. E. Minnikin. London: Academic Press.

Goren, M. B. \& Brennan, P. J. (1979). Mycobacterial lipids: chemistry and biologic activities. In Tuberculosis, pp. 63-193. Edited by G. P. Youmans. Philadelphia: W. B. Saunders

JACIN, H. \& Mishkin, A. R. (1965). Separation of carbohydrates on borate-impregnated silica gel $G$ plates. Journal of Chromatography 18, 170) 173.
KaTES, M. (1972). Techniques of Lipidology: Amsterdam: North-Holland.

Minnikin, D. E. (1982). Lipids: complex lipids, their chemistry, biosynthesis and roles. In The Biology of the Mycohacteria, vol. 1, pp. 95 184. Edited by C. Ratledge \& J. L. Stanford. London: Academic Press.

Minnikin, D. E., Dobson, G. \& Hutchison, I. G. (1983). Characterization of phthiocerol dimycocerosates from Mycohacterium tuherculosis. Biochimica et biophisica acia 753, 445-449.

Minnikin, D. E., ODonnell, A. G., Goodfellow, M., Alderson, G., Athalye, M., Schaal, A. \& Parlett, J. H. (1984). An integrated procedure for the extraction of bacterial isoprenoid quinones and polar lipids. Journal of Microbiological Methods 2. 233241

Miwa, T.K., Mikolajczak, K. L., Earle, F. R. \& WOLfF, I. A. (1960). Gas chromatographic characterization of fatty acids. Analitical Chemistry 32 . 17391742 .

NoLl, H. (1957). The chemistry of some native constituents of the purified wax of Mlcohacterium tuherculosis. Journal of Biological Chemistry 224, 149. 164.

Rafidinarivo, F., Savagnac, A., Lacave, C. \& Promé, J. C. (1982). Branched fatty acids from Micohacterium aturum. Biochimica et hiophysica acta 711, 266271

Reggiardo, Z., Aber, V. R., Mitchison, D. A. \& DEvi, S. (1981). Hemagglutination tests for tuberculosis with mycobacterial lipid glycolipid antigens American Revien' of Respiratory Disease's 124, 2125 